\title{
Pendekatan linguistik korpus untuk kajian metafora konseptual Bahasa Indonesia
}

Gede Primahadi Wijaya Rajeg 1 \& I Made Rajeg 2

Universitas Udayana, Indonesia 1,2

https://orcid.org/0000-0002-2047-8621 1 \& https://orcid.org/0000-0001-8989-0203 2

\begin{abstract}
Abstrak
Makalah ringkas ini merupakan kajian pustaka terhadap kajian metafora konseptual Bahasa Indonesia yang dilandasi atas pendekatan linguistik korpus kuantitatif. Pemahaman dan komponen-komponen mendasar metafora berdasarkan Teori Metafora Konseptual (TMK) diulas dan dikaitkan dengan implikasi metodologis dalam hal strategi pencarian data metafora linguistik dalam korpus. Selanjutnya, pembahasan mencakup hasil-hasil kajian linguistik korpus untuk metafora emosi Bahasa Indonesia, dan implikasi pendekatan linguistik korpus kuantitatif terhadap isu teoretis dalam TMK.
\end{abstract}

Kata kunci: Teori Metafora Konseptual, Linguistik Korpus Kuantitatif, Analisis Pola Metaforis, Metafora Emosi, Bahasa Indonesia

\section{Pendahuluan}

Teori Metafora Konseptual (TMK) (Lakoff \& Johnson 1980; Lakoff \& Johnson 1999) menyatakan bahwa metafora bukanlah semata-mata unsur kebahasaan untuk tujuan retoris, tapi merupakan elemen fundamental dari kognisi manusia yang menuntun bagaimana kita berpikir dan bertindak. Metafora linguistik (§2.1) merupakan salah satu manifestasi dari metafora yang ada dalam pikiran, atau yang disebut metafora konseptual (periksa $§ 2$ untuk paparan lebih rinci terkait TMK). Sebagai contoh, pemahaman kita terhadap konsep IDE umumnya dilandasi atas metafora OBJEK FISIK (Lakoff \& Johnson 1999). Metafora linguistik seperti "ide itu tidak bisa ditangkap maksudnya", "melontarkan ide", "idenya tidak keluar", “mendapatkan ide", "penjelasannya masuk kuping kanan dan keluar kuping kiri” menunjukkan bahwa ide dianggap sebagai suatu objek fisik yang dapat dimanipulasi. 
Perkembangan termutakhir kajian metafora adalah memanfaatkan data kebahasaan elektronik atau korpus (Stefanowitsch \& Gries 2006; Deignan 2005). Makalah ini merupakan kajian pustaka ringkas, dan mengulas kajian-kajian metafora dari sudut pandang TMK yang menerapkan metode dan teknik linguistik korpus. Pembahasan dalam makalah ini berpusat pada strategi pencarian metafora linguistik dalam korpus (§3.1), dan kajian-kajian metafora Bahasa Indonesia, khususnya metafora emosi, berdasarkan pendekatan linguistik korpus (Rajeg 2013; Rajeg 2014; Rajeg 2019; Siahaan 2008; Yuditha 2013).

\section{Metafora konseptual dan metafora linguistik}

Teori Metafora Konseptual (TMK) (Lakoff \& Johnson 1980; Lakoff \& Johnson 1999) dipayungi oleh pendekatan linguistik yang lebih luas, yang disebut Linguistik Kognitif (mis. Croft \& Cruse 2004; Geeraerts \& Cuyckens 2007; Evans \& Green 2006). Seperti yang telah disebutkan di awal §1, pendekatan kognitif terhadap metafora seperti TMK menekankan hakikat utama metafora sebagai sebuah fenomena dan sistem kognitif fundamental bagi manusia (Lakoff \& Johnson 1980: 4; Lakoff \& Johnson 1999: 118). Kajian multidisipliner terhadap metafora menemukan bahwa metafora merupakan hasil dari interaksi kompleks antara "otak, tubuh, bahasa, dan budaya" (Gibbs 2008).

Secara lebih khusus, TMK memandang metafora sebagai mekanisme kognitif guna memahami/mengonseptualisasikan suatu ranah konseptual, yang biasanya bersifat abstrak (disebut ranah target [target domain]), berdasarkan pengetahuan dari ranah konseptual lainnya, yang umumnya bersifat badaniah dan konkret (disebut ranah sumber [source domain]) (Kövecses 2010: 4; Lakoff \& Johnson 1999: 45). Salah satu contoh telah diberikan pada $§ 1$ terkait pemahaman terhadap IDE (ranah target abstrak) berdasarkan konsep OBJEK FISIK (ranah sumber yang konkret).

Metafora konseptual IDE ADALAH OBJEK FISIK ini kemudian dapat tercermin dan diwujudkan secara linguistik oleh metafora linguistik (metaphorical linguistic expression), 
seperti yang telah ditampilkan di awal $§ 1$. Metafora linguistik adalah "kata-kata atau ekspresi linguistik lainnya yang berasal dari dan mencerminkan ranah konseptual yang lebih konkret" (Kövecses 2010: 4), yaitu ranah sumber. Pada kasus metafora IDE ADALAH OBJEK FISIK, kalimat seperti "maksud dari ide itu tidak bisa ditangkap" secara lebih khusus menunjukkan bahwa pemahaman terhadap suatu ide diungkapkan layaknya objek yang dimanipulasi (dalam hal ini menangkapnya). Contoh lain metafora linguistik dalam Bahasa Indonesia adalah ekspresi untuk membicarakan aspek dari AMARAH (ranah target abstrak) menggunakan kata dan frasa yang merujuk ranah sumber API (ranah sumber):

(1) Seluruh badanku panas! Panas terbakar api amarah. (Rajeg 2013: 109)

(2) Karena pada saat itu api kemarahan berkobar membakar darah di hati. (Rajeg 2014 Tabel 1)

(3) Sesungguhnya sedekah yang dilakukan secara diam-diam dapat memadamkan kemurkaan Allah Azza wa Jalla. (Rajeg 2014 Tabel 1)

Berdasarkan contoh metafora linguistik pada (1) - (3), analis akan mengajukan metafora konseptual seperti AMARAH ADALAH API.

\subsection{Bentuk utama metafora linguistik}

Stefanowitsch (2006a: 65) mengajukan dua bentuk utama metafora linguistik. Bentuk pertama adalah metafora linguistik yang hanya mengandung unsur leksikal dari ranah sumber, sedangkan bentuk kedua adalah metafora linguistik yang mengandung unsur leksikal dari ranah sumber dan ranah target. Perhatikan contoh-contoh berikut.

(4) Bahasa Bali (Rajeg 2010)

Ngerodok basange ningehang petane. AV.boil.up stomach.DEF AV.hear words.DEF 'Perutku meluap mendengarkan kata-katanya.' 
(5) Bahasa Bali (Rajeg 2010)

Merasa makeplug tenase baan munyine latek-latek.

feel MID.explode head.DEF because word.DEF rough

'Kepalaku terasa seperti meledak ketika mendengar kata-kata kasarnya.'

(6) Winne sudah lebih dulu meluapkan kemarahannya kepada Arisna. (Rajeg 2013: 109)

(7) Memuntahkan lahar amarah. (Rajeg 2013: 111)

Semua contoh di atas sama-sama merupakan manifestasi dari metafora AMARAH ADALAH CAIRAN PANAS DALAM WADAH yang terdapat pada dua bahasa berbeda.

Kalimat Bahasa Bali pada (4) dan (5) hanya mengandung unsur leksikal dari ranah sumber (ngerodok dan makeplug). Di sisi lain, kalimat (6) dan (7) secara eksplisit mengandung unsur leksikal dari ranah sumber (meluapkan, memuntahkan lahar) dan target (kemarahan, amarah) yang terkait secara sintaksis dalam metafora linguistik tersebut. Kemarahan adalah objek langsung dari meluapkan, sedangkan amarah adalah penjelas nomina dalam frasa nomina lahar amarah, dengan inti lahar; frasa ini kemudian berperan sebagai objek langsung dalam konstruksi transitif dengan verba memuntahkan sebagai inti.

Metafora linguistik seperti pada (6) dan (7) oleh Stefanowitsch (2006a: 66) disebut dengan pola metaforis (metaphorical patterns), yang dipahami sebagai ekspresi multi-kata yang mengacu pada ranah sumber dengan slot-slot sintaksis yang dapat diisi oleh unsur leksikal dari ranah target. Metafora linguistik baik yang berupa pola metaforis ataupun bukan ((4) dan (5)) merupakan data utama dalam mengidentifikasi metafora konseptual. Kedua bentuk utama metafora linguistik tersebut memiliki implikasi metodologis terkait strategi untuk mengkaji metafora konseptual menggunakan pendekatan linguistik korpus (§3.1).

\section{Pembahasan}

\subsection{Strategi utama menggali metafora linguistik dalam korpus}


Linguistik Korpus (LKorp) merupakan suatu paradigma empiris termutakhir dalam linguistik yang berkembang pesat sejak awal tahun 90an (McEnery \& Hardie 2012). Istilah korpus sendiri merupakan kumpulan data bahasa elektronik dalam jumlah besar yang dapat diproses menggunakan komputer. LKorp telah berhasil digunakan dalam mengkaji semua aspek linguistik (dari leksik ke tata bahasa) dan penggunaan bahasa.

Mengingat metafora dalam TMK dipandang utamanya sebagai suatu fenomena konseptual (dengan metafora linguistik bersifat sekunder) dan tidak secara khusus dikaitkan dengan bentuk linguistik tertentu, timbul pertanyaan terkait bagaimana data metafora linguistik yang relevan dapat digali dari korpus. Unsur-unsur pembentuk dua jenis metafora linguistik yang diulas pada $\$ 2.1$ memungkinkan penggunaan salah satu teknik dari LKorp digunakan untuk mengkaji metafora konseptual. Oleh karena itu, dua strategi utama telah diterapkan dalam kajian metafora konseptual berbasis LKorp (Stefanowitsch 2006b).

Strategi pertama menggunakan kata-kata potensial dari ranah sumber untuk menjadi kata kunci pencarian kalimat-kalimat metaforis potensial dalam korpus yang mengandung kata-kata ranah sumber tersebut. Ini dikarenakan metafora linguistik akan selalu mengandung unsur leksikal dari ranah sumber (hal itulah yang pada intinya menyebabkannya menjadi ungkapan metaforis). Langkah selanjutnya adalah menganalisis ranah target dan metafora konseptual apakah yang diacu oleh metafora linguistik yang mengandung unsur leksikal ranah sumber tersebut (periksa (4) dan (5)) (Stefanowitsch 2005; Deignan 2006). Sebagai contoh dalam Bahasa Inggris, Deignan (2006) mengkaji makna metaforis kata flame 'api’ dari ranah sumber API. Flame dikaji berdasarkan perluasan maknanya ke beragam ranah target, seperti EMOSI dan RELIGI. Yang juga menarik dari temuan Deignan (2006) terkait flame adalah adanya interaksi unsur grammatikal dan makna metaforis. Ketika flame metaforis muncul dalam bentuk jamak flames, kata ini cenderung berasosiasi negatif dibandingkan ketika muncul dalam bentuk tunggal (periksa Rajeg \& Rajeg 2019 untuk kajian 
serupa terkait interaksi antara makna (non-)metaforis dan bentuk morfosintaksis suatu kata pada kasus Bahasa Indonesia).

Strategi kedua terkait dengan salah satu unsur pembentuk pola metaforis, yaitu unsur leksikal ranah target. Jadi, strategi kedua adalah menggunakan unsur leksikal yang langsung mengacu ke konsep ranah target (misalnya kata amarah, kemarahan yang mengacu pada konsep MARAH) sebagai kata kunci pencarian kalimat dalam korpus. Langkah selanjutnya adalah peneliti mengidentifikasi kalimat-kalimat relevan di mana unsur leksikal ranah target tersebut berkolokasi secara sintaksis dengan unsur leksikal dari ranah sumber. Strategi yang berpijak pada leksikon ranah target disebut Analisis Pola Metaforis (metaphorical pattern analysis) (Stefanowitsch 2004; Stefanowitsch 2006a). Sebagai contoh, kata dari ranah target KEBAHAGIAAN Bahasa Inggris, seperti happiness, joy, dapat ditelusuri konteks pemakaiannya di dalam korpus, khususnya pola kolokasi leksikon ranah target tersebut dalam bentuk pola metaforis dengan kata-kata dari ranah sumber (mis. bubble with joy 'berbuih-buih dengan kegembiraan'; outpouring of joy 'limpahan kegembiraan'; source of happiness 'sumber kebahagiaan'; pola metaforis ini mencerminkan ranah sumber CAIRAN DALAM WADAH) (Stefanowitsch 2004: 138).

Kedua strategi tersebut memungkinkan dua jalur kajian metafora, yaitu kajian dari sudut pandang ranah sumber dan sudut pandang ranah target. Pembahasan pada $\S 3.2$ mengulas penerapan kedua strategi tersebut pada kajian linguistik korpus untuk metafora Bahasa Indonesia.

\subsection{Kajian metafora Bahasa Indonesia melalui pendekatan linguistik korpus}

Terdapat dua sudut pandang kajian metafora Bahasa Indonesia yang telah dilakukan. Keduanya mencerminkan dua strategi umum yang dibahas pada §3.1. Satu studi berpusat pada ranah sumber ANGGOTA TUBUH/BADAN MANUSIA atau ranah sumber SUHU (temperature) 
(Siahaan 2008; Siahaan 2011; Siahaan 2015) (§3.2.1), sedangkan sisanya berpusat pada ranah target (§3.2.2) (Rajeg 2013; Rajeg 2014; Rajeg 2019; Yuditha 2013).

\subsubsection{Ulasan kajian metafora Bahasa Indonesia dari sudut pandang ranah sumber}

Siahaan (2008) mengkaji dua hal pokok. Perihal pertama adalah rentang makna metaforis yang dapat diacu oleh metafora linguistik yang mengandung kata hati 'liver' di korpus surat kabar daring. Siahaan (2008) menemukan bahwa ranah target KOGNISI dan EMOSI merupakan ranah target yang umum menjadi perluasan makna hati. Perihal kedua dari Siahaan (2008) adalah motivasi budaya dan etno-religi yang mendasari perluasan metaforis kata hati. Siahaan (2008) berpendapat bahwa kayanya perluasan metaforis unsur leksikal hati di Bahasa Indonesia sekarang ini dilandasi atas peninggalan tradisi religi lama dan kepercayaan religius dari suku-suku kuno di Indonesia. Tradisi ini dikenal dengan istilah liver divination, yang merupakan praktik meramal nasib seseorang dengan melihat fitur-fitur dari organ hati binatang kurban.

Pada tulisan selanjutnya (Siahaan 2011), Siahaan membandingkan pemakaian metaforis antara kepala dan mata dalam Bahasa Indonesia, dan Kopf 'kepala' dan Auge 'mata' dalam Bahasa Jerman. Berdasarkan korpus surat kabar daring dan analisis kuantitatif, Siahaan menemukan bahwa perluasan metaforis leksikon anggota badan tersebut memiliki landasan berbeda. Perluasan dominan dari kepala sebagai 'pemimpin' dipandang dilandasi atas aspek posisi dari kepala sebagai bagian teratas dari tubuh manusia. Di sisi lain, 60\% sitiran metaforis dengan Kopf mengungkapkan makna 'pusat dari pikiran'; Siahaan (2011) mengajukan bahwa perluasan terkait kognisi tersebut dilandasi atas fungsi dari Kopf. Perbedaan serupa di antara kedua bahasa juga ditemukan pada kata mata dan Auge. Perluasan makna mata lebih banyak mengeksploitasi bentuk dan ukuran mata itu sendiri (mis. mata kaki, mata air, mata hati, mata pencarian, mata uang), sedangkan Auge memfokuskan pada fungsi dari mata itu sendiri (periksa lebih lanjut Siahaan 2011). 
Kajian lain dari Siahaan adalah pemakaian metaforis unsur leksikal pada ranah SUHU. Siahaan (2015) menemukan bahwa ranah target EMOSI atau KURANGNYA EMOSI adalah yang paling sering muncul dalam pemakaian leksikon SUHU dalam korpus.

Ulasan terhadap penelitian Siahaan menunjukkan bahwa strategi pertama berpijak pada ranah sumber dan memiliki potensi untuk mengidentifikasi rentang dan jenis perluasan makna leksikon ranah sumber tersebut. Selanjutnya, penerapan metode LKorp memungkinkan pemanfaatan data frekuensi yang diperoleh untuk mengetahui perluasan makna metaforis mana yang dominan muncul dalam korpus.

\subsubsection{Ulasan kajian metafora Bahasa Indonesia dari sudut pandang ranah target}

Yuditha (2013) menganalisis konseptualisasi metaforis konsep EMOSI Bahasa Indonesia, khususnya MARAH, CINTA, dan BENCI. Tema utama penelitian ini adalah kesemestaan dan keunikan metafora emosi tersebut dibandingkan dengan metafora emosi serupa yang diajukan pada literatur sebelumnya di Bahasa Inggris. Meskipun Yuditha menyebutkan menggunakan Analisis Pola Metaforis (Stefanowitsch 2006a), data korpus utamanya digunakan untuk memberikan dukungan deskriptif, tanpa kuantifikasi, terhadap tiga metafora yang telah diajukan sebelumnya oleh Kövecses (2008), yaitu CAIRAN, OBJEK (TIDAK )BERHARGA, dan PERSONIFIKASI. Kajian yang diulas berikut ini memanfaatkan analisis kuantitatif dalam menjawab isu-isu teoretis dalam kajian metafora emosi dalam TMK.

Disertasi oleh Rajeg (2013) merupakan yang pertama untuk kajian metafora emosi Bahasa Indonesia yang menggunakan analisis statistik, yaitu Configural Frequency Analysis (CFA) (periksa Gries 2009 Bab 5 untuk ulasan CFA). Rajeg (2013) menerapkan Analisis Pola Metaforis untuk meneliti metafora AMARAH/KEMARAHAN, KETAKUTAN, KEBAHAGIAAN, KESENANGAN, dan CINTA. Yang menarik dari kajian ini adalah penerapan CFA untuk menganalisis frekuensi kemunculan suatu metafora dengan suatu konsep emosi. Secara khusus, CFA digunakan untuk menjawab isu terkait adanya metafora yang khas berasosiasi 
dengan suatu emosi tapi tidak dengan emosi lainnya (Kövecses 1998; Stefanowitsch 2006a). Sebagai contoh, metafora AMARAH/KEMARAHAN ADALAH CAIRAN PANAS DALAM WADAH adalah salah satu metafora yang secara signifikan kuat berasosiasi dengan AMARAH di Bahasa Indonesia (Rajeg 2013: 211), temuan serupa untuk AMARAH dalam Bahasa Inggris (Stefanowitsch 2006a). Lebih lanjut, CINTA secara kuat berasosiasi dengan metafora PERGERAKAN KE BAWAH (mis. jatuh cinta) dan CINTA ADALAH IKATAN FISIK (mis. jalinan/tali cinta) (Rajeg 2013: 222).

Selanjutnya, isu lain yang dapat dikaji melalui pendekatan korpus kuantitatif dan Analisis Pola Metaforis adalah pertanyaan terkait metafora khas yang membedakan sejumlah leksikon yang mengacu pada satu ranah target yang sama (yaitu, leksikon ranah target bersinonim) (Kövecses 1990; Stefanowitsch 2004). Dengan kata lain, interaksi antara metafora dan sinonim ranah target dapat dikaji. Isu inilah yang menjadi perhatian dari Rajeg (2014; 2019), yang merupakan dua kajian pertama yang melihat isu interaksi metafora dan sinonim dalam Bahasa Indonesia.

Analisis awal oleh Rajeg (2014) menemukan bahwa nomina bersinonim untuk AMARAH dalam Bahasa Indonesia memiliki ketertarikan berbeda secara statistik terhadap metafora tertentu; hal ini menunjukkan perbedaan semantis dari masing-masing sinonim. Kajian yang lebih komprehensif dilanjutkan terhadap sinonim KEBAHAGIAAN Bahasa Indonesia (Rajeg 2019). Rajeg (2019) membandingkan sepuluh sinonim KEBAHAGIAAN berdasarkan kekhasan statistik metafora-metafora KEBAHAGIAAN terhadap sinonim tersebut. Ditemukan bahwa profil metaforis masing-masing sinonim berbeda (periksa Rajeg 2019 Bab 7 untuk ulasan lebih rinci).

Sebagai contoh, kebahagiaan secara kuat berasosiasi dengan metafora yang mengkonseptualisasikan kebahagiaan sebagai tujuan akhir dari suatu perjalanan dan memfokuskan unsur pencaipaiannya (mencapai/sampai pada/meraih/menemukan 
kebahagiaan). Kesenangan juga ditemukan berasosiasi kuat dengan metafora pergerakan tersebut namun memfokuskan pada unsur pencariannya (mencari/mengejar kesenangan; kesenangan yang X cari[-cari]). Di sisi lain, kesenangan juga disemati nuansa yang bersifat negatif mengingat kuatnya asosiasinya dengan metafora seperti KESENANGAN ADALAH PENIPU (kesenangan yang menipu; terpesona oleh kesenangan) dan KESENANGAN ADALAH ATASAN (SUBJUGATOR) (mis. diperbudak oleh kesenangan, mendewakan kesenangan). Selanjutnya, kegembiraan secara kuat berasosiasi dengan metafora CAIRAN DALAM WADAH (kegembiraan terpancar; luapan kegembiraan) termasuk tipe khususnya yang melibatkan PANAS, yaitu CAIRAN PANAS DALAM WADAH (meluapkan kegembiraan; kegembiraan meluap[-luap]). Metafora ini menunjukkan profil lebih intens-nya kegembiraan.

Aspek penting lainnya yang dapat dikaji dengan menerapkan Analsisi Pola Metaforis terhadap sejumlah leksikon dari satu ranah target (mis. KEBAHAGIAAN) adalah data dari keseluruhan sinonim dapat digabungkan untuk mewakili ranah target generik yang lebih luas. Agregasi data tersebut menghindari ketimpangan apabila tujuan utamanya menganalisis ranah target secara umum tapi hanya berlandaskan pada satu kata yang mewakili ranah target tersebut (periksa Rajeg 2019 Bab 6 untuk ulasan lebih rinci). Selanjutnya, data kuantitatif yang diperoleh dari kajian korpus dapat diolah sedemikian rupa untuk menjawab isu-isu teoretis dalam TMK (seperti isu-metafora spesifik antar emosi yang dikaji oleh Rajeg 2013; atau isu metafora khas yang mencirikan perbedaan emosi bersinonim dalam kajian Rajeg 2019).

\section{Simpulan}

Makalah ringkas ini mengulas pemahaman termutakhir terhadap metafora berdasarkan Teori Metafora Konseptual (TMK) (§2) serta kajiannya yang dilandasi atas pendekatan Linguistik Korpus. Unsur-unsur linguistik yang mencerminkan komponen metafora konseptual, yaitu leksikon ranah sumber dan leksikon ranah target (§2.1), memungkinkan dua strategi umum 
untuk menggali data metafora linguistik dalam korpus (§3.1), meskipun pada dasarnya TMK tidak mengindikasikan adanya kaitan yang khusus antara suatu metafora konseptual dengan bentuk linguistik tertentu. Selanjutnya, $§ 3.2$ mengulas dua sudut pandang kajian metafora berdasarkan linguistik korpus, utamanya kajian metafora emosi, yang telah dilakukan sejauh ini untuk Bahasa Indonesia: kajian yang dilandasi leksikon ranah sumber (§3.2.1) dan leksikon ranah target (§3.2.2). Dari ulasan kedua sudut pandang kajian tersebut, kami menonjolkan bagaimana informasi kuantitatif yang diperoleh melalui kajian korpus dapat membantu menjawab dan mengoperasionalkan isu-isu teoretis dalam TMK (Stefanowitsch 2006b). Kajian lanjutan untuk metafora Bahasa Indonesia menggunakan pendekatan linguistik korpus kuantitatif masih sangat perlu dilakukan di masa mendatang.

\section{Daftar pustaka}

Croft, William \& D. Alan Cruse. 2004. Cognitive linguistics. Cambridge: Cambridge University Press. (8 December, 2014).

Deignan, Alice. 2005. Metaphor and corpus linguistics. Amsterdam/Philadelphia: John Benjamins Publishing Company.

Deignan, Alice. 2006. The grammar of linguistic metaphors. In Anatol Stefanowitsch \& Stefan Th. Gries (eds.), Corpus-based approaches to metaphor and metonymy, 106122. Berlin: Mouton de Gruyter.

Evans, Vyvyan \& Melanie Green. 2006. Cognitive linguistics: An introduction. Edinburgh: Edinburgh University Press.

Geeraerts, Dirk \& Hubert Cuyckens (eds.). 2007. The Oxford Handbook of Cognitive Linguistics. Oxford: Oxford University Press.

Gibbs, Raymond W. 2008. Metaphor and thought: The state of the art. In Raymond W. Gibbs (ed.), The Cambridge handbook of metaphor and thought, 3-13. Cambridge: Cambridge University Press. 
Gries, Stefan Th. 2009. Statistics for linguistics with R: A practical introduction. Berlin: Mouton de Gruyter.

Kövecses, Zoltán. 1990. Emotion concepts. New York, NY: Springer.

Kövecses, Zoltán. 1998. Are there any emotion-specific metaphors? In Angeliki Athanasiadou \& Elżbieta Tabakowska (eds.), Speaking of emotions: Conceptualisation and expression (Cognitive Linguistics Research 10), 127-151. Berlin: Mouton de Gruyter.

Kövecses, Zoltán. 2008. Metaphor and emotion. In Raymond W. Gibbs (ed.), The Cambridge handbook of metaphor and thought, 380-396. Cambridge: Cambridge University Press.

Kövecses, Zoltán. 2010. Metaphor: A practical introduction. 2nd edn. Oxford: Oxford University Press.

Lakoff, George \& Mark Johnson. 1980. Metaphors we live by. Chicago: The University of Chicago Press.

Lakoff, George \& Mark Johnson. 1999. Philosophy in the flesh: The embodied mind and its challenge to Western thought. New York: Basic Books.

McEnery, Tony \& Andrew Hardie. 2012. Corpus linguistics: Method, theory and practice. Cambridge: Cambridge University Press.

Rajeg, Gede Primahadi Wijaya. 2014. Metaphorical profiles of five Indonesian quasisynonyms of ANGER: Multiple distinctive collexeme analysis. Proceedings of the International Congress of the Linguistic Society of Indonesia 2014, 165-170. Bandar Lampung, Sumatra, Indonesia: Masyarakat Linguistik Indonesia (MLI). doi:10.4225/03/58578ddba1fd2. 
Rajeg, Gede Primahadi Wijaya. 2019. Metaphorical profiles and near-synonyms: A corpusbased study of Indonesian words for HAPPINESS. Clayton, VIC: Monash University, Australia PhD thesis. doi:10.26180/5cac231a97fb1.

Rajeg, Gede Primahadi Wijaya \& I Made Rajeg. 2019. Pemahaman kuantitatif dasar dan penerapannya dalam mengkaji keterkaitan antara bentuk dan makna. Linguistik Indonesia 37(1). 13-31. doi:10.26180/5c6e1160b8d8a.

Rajeg, I Made. 2010. “Kebus Basange”: Metaphoric and metonymic conceptualisation of ANGER in Balinese. Presented at the Seminar Nasional Bahasa Ibu III (The 3rd National Seminar on Mother Tounge), Denpasar, Bali.

Rajeg, I Made. 2013. Metafora emosi Bahasa Indonesia. Denpasar, Bali, Indonesia: Universitas Udayana Disertasi doktoral. doi:10.6084/m9.figshare.7886180.

Siahaan, Poppy. 2008. Did he break your heart or your liver? A contrastive study on metaphorical concepts from the source domain ORGAN in English and in Indonesian. In Farzad Sharifian, René Dirven, Ning Yu \& Susanne Niemeier (eds.), Culture, body, and language. Conceptualizations of internal body organs across cultures and languages, 45-74. Berlin: Mouton de Gruyter.

Siahaan, Poppy. 2011. HEAD and EYE in German and Indonesian figurative uses. In Zouheir A. Maalej \& Ning Yu (eds.), Embodiment via Body Parts: Studies from various languages and cultures, 93-114. Amsterdam/Philadelphia: John Benjamins Publishing Company.

Siahaan, Poppy. 2015. Why is it not cool? Temperature terms in Indonesian. In Maria Koptjevskaja-Tamm (ed.), The Linguistics of Temperature, 666-699. Amsterdam: John Benjamins Publishing Company. 
Stefanowitsch, Anatol. 2004. HAPPINESS in English and German: A metaphorical-pattern analysis. In Michel Achard \& Suzanne Kemmer (eds.), Language, Culture, and Mind, 137-149. Stanford, CA: CSLI.

Stefanowitsch, Anatol. 2005. The function of metaphor: Developing a corpus-based perspective. International Journal of Corpus Linguistics 10(2). 161-198.

Stefanowitsch, Anatol. 2006a. Words and their metaphors: A corpus-based approach. In Anatol Stefanowitsch \& Stefan Th. Gries (eds.), Corpus-based approaches to metaphor and metonymy, 63-105. Berlin: Mouton de Gruyter.

Stefanowitsch, Anatol. 2006b. Corpus-based approaches to metaphor and metonymy. In Anatol Stefanowitsch \& Stefan Th. Gries (eds.), Corpus-based approaches to metaphor and metonymy, 1-16. Berlin: Mouton de Gruyter.

Stefanowitsch, Anatol \& Stefan Th. Gries (eds.). 2006. Corpus-based approaches to metaphor and metonymy. Berlin: Mouton de Gruyter.

Yuditha, Tessa. 2013. Indonesian metaphorical conceptualizations of ANGER, LOVE, and HATE: An overview. Paper presented at the International Workshop on "Special Genres" in and around Indonesia, Tokyo, Japan. http://repository.tufs.ac.jp/bitstream/10108/75521/1/B130_123-142.pdf (23 June, 2015). 